\title{
TRANSMISSÃO TRANSOVARIANA DE Babesia bovis EM Boophilus microplus: OBTENÇÃO DE CEPA DE CARRAPATO LIVRE DE Babesia spp.
}

\author{
Babesia bovis TRANSOVARIAN TRANSMISSION IN Boophilus microplus: \\ OBTENTION OF A Babesia FREE TICK STRAIN.
}

\author{
Tânia Regina Bettin dos Santos ${ }^{1}$ João Carlos Gonzales ${ }^{2}$ \\ Jocelei Maria Chies ${ }^{3}$ Nara Amélia da Rosa Farias ${ }^{4}$
}

\section{RESUMO}

O presente trabalho objetivou o estudo de parte do ciclo da Babesia bovis no seu hospedeiro invertebrado, o carrapato Boophilus microplus. Analisou-se a capacidade de infeccção e transmissão transovariana de $\boldsymbol{B}$. bovis em partenóginas de B. microplus, alimentadas em bovinos portadores e enfermos por esse protozoário. No $18^{\circ}$ dia após a infestação, coletaram-se partenóginas diretamente do corpo dos bovinos e teleóginas após o desprendimento natural, a partir do $21^{0}$ dia. Todos os grupos foram incubados a $27^{\circ} \mathrm{C}$ e umidade relativa superior a $70 \%$. No $5^{0}$ dia após o início da postura, realizou-se o exame de hemolinfa a fim de diagnosticar a infecção dos ínstares por B. bovis. A ausência de infecção detectada no exame de hemolinfa foi confirmada posteriormente com o teste biológico, revelando que partenóginas não transmitem $\boldsymbol{B}$. bovis transovarianamente. Esses resultados oferecem uma técnica simplificada para a obtenção de cepas de carrapatos livres de B. bovis.

Palavras-chave: Boophilus microplus, Babesia spp, biologia transmissão transovariana e cepa livre.

\section{SUMMARY}

In this experiment part of the life cycle of Babesia bovis in its invertebrate host, the tick Boophilus microplus was studied. In order to evaluate the capacity of infection and transmission of $\boldsymbol{B}$. bovis were collected semi-engorged females of B. microplus fed on carrier and ill bovines. In the $18^{\text {th }}$ day after infestation, semi-engorged females were collected directly from bovine bodies and after $21^{\text {st }}$ day engorged females dropped on the ground. All the collected groups were incubated at $27^{\circ} \mathrm{C}$ and relative humidity greater than $70 \%$. At the $5^{\text {th }}$ day of oviposition the diagnosis was made by direct examination of haemolymph smears. The biological test reveled that $\boldsymbol{B}$. bovis transovarial transmission doesn't happer in semi-engorged females. The results offer a simple techique to obtain strains of ticks free of $\boldsymbol{B}$. bovis.

Key words: Boophilus microplus, Babesia spp., biology, transovarian transmission and free strain.

\section{INTRODUÇÃO}

As parasitoses ainda hoje são responsáveis por inúmeros prejuízos na pecuária. Entre elas, o complexo carrapato/Babesia causa perdas como retardo no crescimento, desvalorização na comercialização entre zonas livres e endêmicas, queda na produção, entre outras. O desenvolvimento de Babesia spp. no hospedeiro invertebrado vem sendo estudado desde o início do século e ainda existem controvérsias entre autores, quanto ao período de infecção das fêmeas, à transmissão transovariana do protozoário e quanto à importância dos hospedeiros não habituais na epidemiologia do complexo carrapato/babesiose bovina (RIEK, 1964; RIEK, 1966; YOUNG \& MORZARIA, 1986).

\footnotetext{
${ }^{1}$ Médico Veterinário, MSc., Professor Assistente, Departamento de Medicina Veterinária Preventiva, Faculdade de Veterinária, Universidade Federal de Pelotas (UFPeL), CP 354, 96010-900, Pelotas, RS, Brasil. E-mail: nafarias@ufpel.tche.br. Autor para correspondência.

${ }^{2}$ Médico Veterinário, Dr., Professor Adjunto, Setor de Entomozooses, Faculdade de Veterinária, Universidade federal do Rio grande do Sul (UFRGS), Porto Alegre, RS..

${ }^{3}$ Biólogo, MSc., Pesquisadoro do Centro de Biotecnologia, UFRGS.

${ }^{4}$ Médico Veterinário, Dr., Professor Adjunto, Departamento de Microbiologia e Parasitologia, Instituto de Biologia, UFPel.
} Recebido para publicação em 08.09.98. Aprovado em 11.08.99 
No estudo da infecção das teleóginas, CALLOW (1968), utilizando a técnica de transferência artificial de diferentes estádios de $\boldsymbol{B}$. microplus de bovinos portadores de $\boldsymbol{B}$. bigemina para bovinos livres e sensíveis a Babesia spp., associado ao uso de babesicidas, concluiu que o carrapato somente se infecta com esse protozoário nas últimas 16 a 24 horas de repasto sangüíneo; porém, não são conhecidos os fatores que impedem a infecção anterior a esse período. Podem estar relacionados a uma digestão acelerada que destrói os protozoários (POLIANSKI \& KHEISIN, 1959) ou a transformações das células basofílicas da parede intestinal para a síntese de vitelogenina, que as tornariam suscetíveis à infecção por Babesia spp. (AGBEDE et al., 1986). No entanto, SANTOS et al. (1998), testando a capacidade de transmissão transovariana de $\boldsymbol{B}$. bigemina por partenóginas de $\boldsymbol{B}$. microplus, concluíram que essas fêmeas semi-ingurgitadas, coletadas de bovinos em fase clínica de babesiose, transmitem a infecção à sua progênie, mas aquelas coletadas de bovinos em fase subclínica, não transmitem. SANTOS et al.(1998) concluíram que diante de altas parasitemias, alguns protozoários conseguem infectar as células intestinais de fêmeas coletadas três dias antes de seu ingurgitamento e, posteriormente, atingir seus ovários e ovos. Essa transmissão foi constatada através de testes biológicos em bovinos sensíveis.

MAHONEY \& MIRRE (1977) verificaram que a $\boldsymbol{B}$. bovis começa a ser eliminada nos ovos de teleóginas desprendidas naturalmente do bovino a partir da $24^{\mathrm{a}}$ hora de postura, estando em um percentual crescente até o $5^{\circ}$ dia quando então decresce. CAFRUNE et al. (1995), no entanto, verificaram que esses ovos infectados começam a ser eliminados a partir do $4^{\circ}$ dia de ovopostura. Segundo FRIEDHOFF \& SMITH (1981), a B. bigemina começa a ser eliminada a partir da $16^{\mathrm{a}}$ hora de postura. Assim, os ovos das primeiras horas de postura seriam livres de Babesia spp. FARIAS (1994) constatou a transmissão de $\boldsymbol{B}$. bigemina por larvas originadas de ovos das primeiras 24 horas de postura, sem haver, no entanto, a transmissão de B. bovis.

LARANJA et al. (1975) infestaram ovinos, caprinos, eqüinos e bovinos sensíveis com larvas de $\boldsymbol{B}$. microplus naturalmente infectados com Babesia spp. e Anaplasma marginale. As progênies das teleóginas obtidas nos hospedeiros não habituais foram utilizadas para infestar bovinos sensíveis e não houve transmissão dos agentes da Tristeza Parasitária Bovina. Essa seria uma técnica de obtenção de cepas de $\boldsymbol{B}$. microplus livres de Babesia spp. Entretanto, CALLOW (1965) verificou que as progênies de teleóginas ingurgitadas em eqüinos, ovinos e caprinos transmitem B. bigemina a bovinos sensí- veis. O mesmo foi constatado por FARIAS (1994) quanto à $\boldsymbol{B}$. bovis, após a passagem do carrapato em ovinos.

Esses caracteres biológicos específicos dos protozoários B. bovis e B. bigemina, uma vez bem conhecidos, permitem o isolamento de cepas puras a partir de carrapatos de campo, com infecção mista, e a obtenção de cepas de carrapatos livres de Babesia spp. As cepas de B. microplus não infectadas são imprescindíveis para a maioria dos estudos de biologia e epidemiologia da Babesia spp. Até então, os grupos de pesquisa dependiam de esterilização química do carrapato através de tratamento babesicida do bovino hospedeiro (KUTTLER, 1975 e FARIAS, 1994), ou da obtenção esporádica de cepas naturalmente livres. Baseados nestes dados e nas controvérsias existentes, o presente trabalho objetivou o estudo de parte do ciclo evolutivo da $\boldsymbol{B}$. bovis no seu hospedeiro invertebrado, testando a capacidade de transmissão transovariana por partenóginas de $\boldsymbol{B}$. microplus, e a busca de uma possível técnica simplificada para obter variedades de carrapatos livres de Babesia spp.

\section{MATERIAL E MÉTODOS}

O presente trabalho foi realizado no Setor de Entomozooses da Faculdade de Veterinária da UFRGS, em Porto Alegre, RS, Brasil. Foram utilizados um total de dez terneiros, oriundos de região livre de carrapato, e sorologicamente negativos a Babesia spp. A cepa de carrapato utilizada é originária do município de Santa Vitória do Palmar - RS, e naturalmente livre de Babesia spp. Posteriormente, essa cepa foi infectada com isolado puro de $\boldsymbol{B}$. bovis (FARIAS, 1994). Para a obtenção de carrapatos ingurgitados durante a fase subclínica de babesiose, dois terneiros não esplenectomizados e já portadores de $\boldsymbol{B}$. bovis receberam, cada um, três infestações com 10.000 larvas infestantes em dias alternados. Assim, esses bovinos receberam um total de 30.000 larvas de $\boldsymbol{B}$. microplus infectadas com $\boldsymbol{B}$. bovis. No $12^{\circ}$ dia após a primeira infestação, foram inoculados, via endovenosa, com $6 \mathrm{~m} \ell$ de sangue previamente congelado em nitrogênio líquido, contendo B. bovis entre $15,5 \times 10^{7}$ e $27 \times 10^{7}$ Unidades Infectantes/m $\ell$ de sangue.

As partenóginas (fêmeas semiingurgitadas, com sulcos visíveis) foram coletadas a partir do $18^{\mathrm{o}}$ dia após a primeira infestação, diretamente do corpo do animal, e as teleóginas após seu desprendimento natural do hospedeiro, a partir do $21^{\mathrm{o}}$ dia. Foi considerada fase subclínica, quando os bovinos não apresentavam sinais como queda de hematócrito, elevação de temperatura e era detectada Babesia spp. nos esfregaços sanguíneos. 
Para obtenção de carrapatos ingurgitados durante a fase clínica de babesiose, foram utilizados dois bovinos livres de Babesia spp. e esplenectomizados, os quais foram infestados com larvas também livres de Babesia spp., para que a fase clínica não ocorresse antes do dia modal (dia de maior número de ínstares) de produção de partenóginas e teleóginas. Nesses terneiros foram inoculados $12 \mathrm{~m} \ell$ de sangue congelado em nitrogênio líquido, contendo Babesia bovis entre $15,5 \times 10^{7}$ e $27 \times 10^{7}$ Unidades Infectantes/m $\ell$. As demais etapas, como número de infestações, método de inoculação e coletas de partenóginas e teleóginas foram as mesmas utilizadas para a fase subclínica. Foi considerada fase clínica, quando os bovinos apresentavam sintomas como queda de hematócrito, elevação de temperatura e presença de $\boldsymbol{B}$. bovis nos esfregaços sanguíneos.

Os grupos de partenóginas foram identificados como $\mathrm{P}$ e os de teleóginas como T. De acordo com o grau de infecção dos bovinos (fase subclínica ou fase clínica), por ocasião da coleta dos ínstares de carrapatos, os grupos foram designados de s ou c. Assim, foram formados grupos Ps e Ts (partenóginas e teleóginas, respectivamente, coletadas de bovinos em fase subclínica de $\boldsymbol{B}$. bovis), e grupos Pc e Tc (partenóginas e teleóginas, respectivamente, coletadas de bovinos em fase clínica de B. bovis). Cada grupo (Ps, Ts, Pc, Tc) contou com uma repetição que foi designada de a (Ps e Ts; Psa e Tsa; Pc e Tc; Pca e Tca), para a qual foi utilizado outro bovino infestado com a metodologia referida anteriormente.

Os grupos $\mathrm{P}$ foram constituídos por 20 partenóginas com um peso total de 1 grama e contaram com 7 repetições. Os grupos $\mathrm{T}$, constituídos de 10 teleóginas com peso total de 3 gramas, contaram com 5 repetições. Todos os grupos foram incubados em placas de Petri, a $27^{\circ} \mathrm{C}$ e umidade relativa do ar superior a $70 \%$, e no $5^{\circ}$ dia de postura foram realizados os exames de hemolinfa, baseados em MAHONEY \& MIRRE (1971). Cada partenógina ou teleógina examinada foi considerada infectada ou não, sem ser avaliado o seu nível de infecção, pois, segundo CAFRUNE $\boldsymbol{e t}$ al. (1995) e GUGLIELMONE et al. (1997), essa classificação parece ter maior importância epidemiologica, uma vez que foi detectada baixa relação entre o grau de infecção na hemolinfa e a taxa de infecção nos ovos.

No $20^{\circ}$ dia de postura, foram selecionados os ovos férteis de cada grupo e, após uma homogeneização da massa de ovos, foram incubados em tubos de ensaio, em alíquotas de $0,5 \mathrm{~g}$ a fim de se obterem larvas infestantes para o teste biológico com os bovinos. Foram utilizados 6 bovinos, nos testes biológicos, com aproximadamente 6 meses de idade, e sorologicamente negativos a Babesia spp. Posteriormente, foram esplenectomizados. Os terneiros foram mantidos em baias individuais e isoladas com telas, para evitar infecções acidentais por hematozoários, além de Anaplasma marginale e Eperythrozoon sp. Desses bovinos, 4 foram infestados com larvas oriundas dos grupos $\mathrm{P}$, sendo os demais (2) utilizados para testar a progênie dos grupos $\mathrm{T}$.

Todos os animais utilizados no teste biológico tiveram acompanhamento clínico diário, até o final da produção de teleóginas (25 - 27 dias pós infestação), através de tomadas de temperatura retal, hematócrito e esfregaço sanguíneo, observando-se, assim, a inoculação ou não de Babesia bovis pela progênie dos diferentes grupos. Para os testes sorológicos, foram coletados $20 \mathrm{~m} \ell$ de sangue sem anticoagulante de cada bovino utilizado no teste biológico, antes de serem infestados e 30 dias após o término de produção de teleóginas.O soro oriundo desse sangue, após centrifugação, foi enviado para o Instituto de Pesquisas Desidério Finamor - Guaíba - RS, onde foi realizado o teste de ELISA, segundo ROITT et al. (1989), para a detecção de anticorpos anti-Babesia.

\section{RESULTADOS E DISCUSSÃO}

Na tabela 1, observa-se que as partenóginas coletadas de bovinos em fase subclínica por $\boldsymbol{B}$. bovis (grupos Ps e Psa) foram negativas no exame de hemolinfa. A ausência da infecção e, consequientemente, de transmissão transovariana, foi confirmada pelo acompanhamento clínico dos bovinos utilizados no teste biológico. A prova sorológica revelou ausência de anticorpos anti-Babesia nesses animais, o que confirma a ausência de $\boldsymbol{B}$. bovis na progênie das partenóginas.

Tabela 1 - Infecção de partenóginas e teleóginas de Boophilus microplus, alimentadas em bovinos na fase subclínica de babesiose por Babesia bovis, e a capacidade de transmissão do protozoário.

\section{Grupo \% de ínstares positivos Teste Biológico Elisa B. bigemina} ao exame de hemolinfa B. bovis

\begin{tabular}{lcccc}
\hline & & & & \\
Ps & 00 & - & - & - \\
Ts & 16 & - & + & - \\
Psa & 00 & $+*$ & NR & NR \\
Tsa & 09 & & & \\
\hline
\end{tabular}

Ps - Partenóginas coletadas de bovinos com Babesia bovis em fase subclínica. Ts - Teleóginas coletadas de bovinos com Babesia bovis em fase subclínica. a - repetição.

* - Morreu durante a fase aguda da doença.

NR - Não realizado. 
As teleóginas, de ambos os grupos, (Ts e Tsa), foram positivas e revelaram no exame de hemolinfa um percentual de infecção de $16 \%$ e $9 \%$ respectivamente (Tabela 1). No teste biológico, demonstraram transmissão de $\boldsymbol{B}$. bovis para os bovinos, sendo que o período de incubação variou entre 9 e 12 dias, com temperatura retal atingindo $41,3^{\circ} \mathrm{C}$. Esses resultados confirmam os dados descritos por MAHONEY (1977), quanto ao período de incubação.

O teste sorológico revelou a presença de anticorpos anti-B. bovis e a ausência de anticorpos anti-B. bigemina, confirmando que a infecção dessa cepa de carrapatos foi exclusivamente por $\boldsymbol{B}$. bovis. Portanto, as partenóginas coletadas de bovinos durante a fase subclínica de $\boldsymbol{B}$. bovis não desenvolveram infecção com esse protozoário, concordando, assim, com os resultados obtidos por CALLOW (1968) quanto a B. Bigemina; segundo esse autor somente nas últimas 16 a 24 horas de hematofagismo é que o carrapato se infecta com o protozoário. Resultados similares foram verificados por SANTOS et al. (1998) os quais constataram que partenóginas de $\boldsymbol{B}$. microplus ingurgitadas em bovinos em fase subclínica de babesiose por $\boldsymbol{B}$. bigemina não transmitem a infecção à sua progênie. As partenóginas não transmitiram $\boldsymbol{B}$. bovis, talvez porque os processos digestivos nas fases iniciais de ingurgitamento sejam mais rápidos, destruindo, assim, os patógenos como sugerem POLIANSKI \& KHEISIN (1959), ou devido às células basofílicas do intestino não estarem suscetíveis à invasão do protozoário (AGBEGE et $\boldsymbol{a l}$. 1986). No entanto, as teleóginas ingurgitadas nesses bovinos durante fase subclínica de $\boldsymbol{B}$. bovis foram capazes de se infectar e transmitir a infecção, confirmando os resultados de CAFRUNE et al. (1995) que constataram infecção por B. bovis em ovos postos por teleóginas ingurgitadas em bovinos com parasitemias entre 0,01 e $0,02 \%$.

No grupo Tsa, (teleóginas coletadas em fase subclínica por B. bovis - repetição) apesar do percentual de infecção relativamente baixo (9\%) das teleóginas em nível de hemolinfa, sua progênie foi capaz de transmitir $\boldsymbol{B}$. bovis no teste biológico. O bovino infestado com essas larvas apresentou sintomas como: anorexia, elevação de temperatura, queda de hematócrito, ataxia e incoordenação motora, também descritos por LOSOS (1986); e no $9^{0}$ dia após a infestação, através de exame direto, foi detectado B. bovis no sangue coletado da veia jugular. Esse período de incubação confirma o descrito por MAHONEY (1977), o qual afirmou que a $\boldsymbol{B}$. bovis alcança níveis detectáveis no sangue periférico entre 8 a 16 dias após a fixação do carrapato.
Na tabela 2, observa-se que os grupos de partenóginas $(\mathrm{Pc}-$ partenóginas coletadas em fase clínica por B. bovis e Pca - repetição) foram negativos no exame de hemolinfa, sendo confirmada a ausência de infecção através do teste biológico, pois os bovinos utilizados não manifestaram alterações significativas de temperatura, hematócrito, e não foi detectado o protozoário no exame direto, nem anticorpos anti-Babesia no teste sorológico.

Os grupos Tc (teleóginas coletadas em fase clínica por $\boldsymbol{B}$. bovis) e Tca (repetição) revelaram no exame de hemolinfa, um percentual de infecção de $80 \%$ e $85 \%$. Esses resultados, quando comparados com os dos grupos Ts e Tsa (percentual de infecção de $16 \%$ e 9\%), - tabela 1, concordam com os de RISTIC et al. (1981), os quais afirmaram que o percentual de fêmeas de carrapato infectadas, depende do grau de parasitemia no sangue do hospedeiro durante o final do ingurgitamento. Assim, não foi realizado o teste biológico da progênie das teleóginas (Tc e Tca), pois os resultados obtidos no exame de hemolinfa confirmaram a infecção do carrapato.

Os resultados foram similares aos constatados nos carrapatos ingurgitados em bovinos em fase subclínica de infecção por $\boldsymbol{B}$. bovis. Esse protozoário, mesmo em fase clínica, atinge parasitemias muito baixas, e os poucos parasitas ingeridos talvez sejam insuficientes para transpor a barreira intestinal descrita por AGBEDE $\boldsymbol{e}$ t al. (1986) e POLIANSKI \& KHEISIN (1959) e atingir o ovário das partenóginas. A transmissão transovariana depende do nível de parasitemia do hospedeiro, o que é confirmado pelo fato de que, nas partenóginas ingurgitadas em bovino em fase clínica por B bigemina (altas parasitemias), alguns protozoários sobrevivem e garantem a transmissão transovariana, enquanto que naquelas ingurgitadas em bovinos em fase subclínica

Tabela 2 - Infecção de partenóginas e teleóginas de Boophilus microplus, alimentadas em bovinos na fase clínica de babesiose por Babesia bovis, e a capacidade de transmissão do protozoário.

\begin{tabular}{ccccc} 
Grupo & $\begin{array}{c}\% \text { de ínstares positivos } \\
\text { ao exame de hemolinfa }\end{array}$ & Teste biológico & $\begin{array}{c}\text { Elisa } \\
\text { B. bovis }\end{array}$ & B. bigemina \\
\hline & & & & \\
Pc & 00 & - & - & - \\
Tc & 85 & $\mathrm{NR}$ & $\mathrm{NR}$ & $\mathrm{NR}$ \\
Pca & 00 & - & - & - \\
Tca & 80 & $\mathrm{NR}$ & $\mathrm{NR}$ & $\mathrm{NR}$ \\
& & & & \\
\hline
\end{tabular}

Pc - Partenóginas coletadas de bovino com Babesia bovis em fase clínica. Tc - Teleóginas coletadas de bovino com Babesia bovis em fase clínica. a - repetição.

NR - Não realizado. 
não ocorreu essa transmissão (SANTOS $\boldsymbol{e t} \boldsymbol{a l}$., 1998). B. bovis, no entanto, não é transmitida transovarianamente por partenóginas se quer ingurgitadas em fase clínica de babesiose. Esses resultados permitem recomendar a utilização de ovos postos por partenóginas (fêmeas semi-ingurgitadas) como uma técnica extremamente simplificada e eficaz para a obtenção de cepa de $\boldsymbol{B}$. microplus livre da infecção por Babesia spp., alternativa para a técnica de utilização dos ovos das primeiras 24 horas de postura, que, segundo FARIAS (1994) podem estar infectadas por B. bigemina.

\section{REFERÊNCIAS BIBLIOGRÁFICAS}

AGBEDE R.I.S., KEMP, D.H., HOYTE, H.M.D. Babesia bovis infection of secretory cells in the gut vector tick Boophilus microplus. International Journal for Parasitology, v.16, n.2 p.109-114, 1986

CAFRUNE, M.M, AGUIRRE, D.H., MANGOLD, A.J., et al. Experimental studies of the rate of infection of Boophilus microplus eggs with Babesia bovis. Research Veterinary Science, v.58, p.284-285, 1995.

CALLOW, L.L. Babesia bigemina in ticks grown on non-bovine host and its transmission to these hosts. Parasitology, v.55, p.375-381, 1965.

CALLOW, L.L. The infection of Boophilus microplus with Babesia bigemina. Parasitology, v.58, p.663-670, 1968.

FARIAS, N.A.R. Efeito diferencial de Babesia bovis e Babesia bigemina sobre a capacidade reprodutiva do vetor Boophilus microplus. Rio de Janeiro, 1994. 134p. Tese (Doutorado em Biologia Parasitária) - Curso de Pós-graduação em Biologia Parasitária, Fundação Oswaldo Cruz, 1994.

FRIEDHOFF, K.T., SMITH, R.D. Transmission of Babesia by ticks. In: RISTIC, M., KREIER, J.P. Babesioses. New York: Academic, 1981. p.267-322.

GUGLIELMONE, A.A., GAIDO, A.B., AGUIRRE, D.H., et al Some quantitative aspects of natural babesial infection in the haemolymph of Boophilus microplus engorged female ticks. Parasite, v.4 p.337 - 341, 1997.

KUTTLER, K.L., GRAHAM, O.H., TREVINO, J.L. The effect of imidocarb treatment on Babesia in the tick (Boophilus microplus). Research Veterinary Science, v.18, p.198-200, 1975.
LARANJA, R., ARRIEGUI, L., ARTECHE, C.C.P. Transmissão dos agentes da tristeza parasitária dos bovinos após passagem de Boophilus microplus em hospedeiros não habituais. Boletim IPVDF, v.3, n.1, p.113-123, 1975.

LOSOS, G.J. Babesiosis. In: LOSOS, G.J. Infections tropical diseases of domestic animals. Canada : Longman Scientific, Technical, 1986. p.1-97.

MAHONEY, D.F., MIRRE, G.B. Bovine babesiosis: Estimation of infection rates in the tick vector Boophilus microplus. Annais of Tropical Medicine and Parasitology, v.65, n.3, p.309-317, 1971.

MAHONEY, D.F. Babesia of domestic animals. In: KREIER, J.P. Parasitic Protozoa. New York : Academic 1977. V.4, Cap.1, p.1-52.

MAHONEY, D.F., MIRRE, G.B. The selection of larvas of Boophilus microplus infected with Babesia bovis (syn. Babesia argentina). Research in Veterinary Science, v.23, p.126-127, 1977.

POLIANSKI, I.I., KHEISIN, E.M. Some observations on the development of Babesia bovis in the tick vector. Karel Fil Akad Nauk v.14, p.5-13. 1959.

RIEK, R.F. The life cycle of Babesia bigemina (Smith, Kilborne,1893) in the tick vector Boophilus microplus (Canestrini,1887). Australian Journal of Agricultural Research, v.15, p.802-821, 1964.

RIEK, R.F. The life cycle of Babesia argentina (Lignieres, 1903) (Sporozoa: Piroplasmidea) in the tick vector Boophilus microplus (Canestrini,1887). Australian Journal of Agricultural Research,v.17, p.247-254, 1966.

RISTIC, M., SMITH, R.D., KAKOMA, I. Characterization of Babesia antigens derived from cell cultures and ticks. In: RISTIC, M. KREIER, J. P. Babesioses. New York : Academic, 1981. p.337-380

ROITT, I.M., BROSTOFF, J., MALE, D.K. Imunologia. São Paulo : Manole, 1989. p.355.

SANTOS, T.R.B., GONZALES, J.C., CHIES, J.M., et al. Transmissão transovariana de Babesia bigemina por partenóginas de Boophilus microplus. Revista Brasileira de Parasitologia Veterinária, v.7, n.1, p.7-10, 1998.

YOUNG, A.S., MORZARIA, S.P. Biology of Babesia. Parasitology Today, v.2, n.8, p.211-219, 1986.

Ciência Rural, v. 30, n. 3, 2000. 